\title{
Statistical Approach to Regulation of Nanotechnology: Need, Advantages and Disadvantages
}

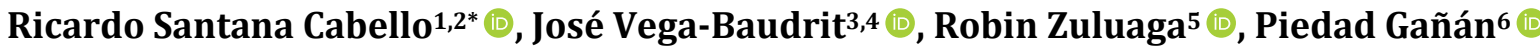 \\ ${ }^{1}$ Deusto Institute of Technology (Deusto Tech), University of Deusto, Bilbao, Spain \\ ${ }^{2}$ New Materials Research Group, Universidad Pontificia Bolivariana, Medellin, Colombia \\ ${ }^{3}$ National Laboratory of Nanotechnology LANOTEC-CENAT-CONARE, Pavas, San José, Costa Rica \\ ${ }^{4}$ POLIUNA, Chemistry School, National University, Heredia, Costa Rica \\ ${ }^{5}$ Faculty of Agro-Industrial Engineering, Universidad Pontificia Bolivariana, Medellin, Colombia \\ ${ }^{6}$ Faculty of Chemical Engineering, Universidad Pontificia Bolivariana, Medellín, Colombia \\ Email: *ricardo.santana.cabello@gmail.com, jvegab@gmail.com
}

How to cite this paper: Cabello, R.S., Vega-Baudrit, J., Zuluaga, R. and Gañán, P. (2020) Statistical Approach to Regulation of Nanotechnology: Need, Advantages and Disadvantages. Journal of Biomaterials and Nanobiotechnology, 11, 14-32. https://doi.org/10.4236/jbnb.2020.111002

Received: September 14, 2019

Accepted: November 15, 2019

Published: November 18, 2019

Copyright $\odot 2020$ by author(s) and Scientific Research Publishing Inc. This work is licensed under the Creative Commons Attribution International License (CC BY 4.0).

http://creativecommons.org/licenses/by/4.0/

\begin{abstract}
The need to have an express regulation covering nanotechnology has been the subject of debate in the scientific literature and identified as one of the main subsets of nanotechnology field research. However, most countries still do not have regulatory framework in order to guarantee consumer safety. This is the case of Costa Rica, one of the most promising countries in Latin America in terms of biotechnology and nanotechnology. This article presents a statistical study about the position of industry, academia and government institutions on the need to expressly regulate nanotechnology in Costa Rica. A qualitative study consisting of a survey of 79 forms was done to individuals representing the community involved with nanotechnology and institutions responsible for ensuring the safety of the citizen's health, to conclude that the nanotechnology regulation should be created to protect the consumer in Costa Rica. The research also proposes aspects that should be taken into account in its drafting as well as the variables on which decisions should be made to authorize the commercialization of nanomaterials based on the findings of the literature.
\end{abstract}

\section{Keywords}

Nanotechnology, Regulation, Security, Consumer

\section{Introduction}

Nanotechnology presents numerous challenges in terms of designing an adequate 
regulation. Therefore, this topic has generated numerous research works that help design an appropriate governance, both in generic and specific contexts. These studies assist policy-makers to adjust the regulatory framework. For instance, [1] presented a method to identify efficiency and reliability of nanotechnology patent information; [2] evaluated trends of worldwide patenting in nanotechnology; [3] collected, processed and analyzed nanopatents to make recommendations to Brazilian government as well as industry. There are studies that highlight the importance of these studies, for instance, [4] suggests that regulation of nanotechnology is one of the main subsets of nanotechnology studies field. Furthermore, [5] detected nanotechnology regulation as a paradigm in techno-scientific literature.

Costa Rica has remarkable position in terms of biotechnology and nanotechnology given the promotion of public policies and the natural context. Nanotechnology is considered one of the priority fields for the development of this country, according to the Strategy of the XXI Century, for the year 2050 [6]. In addition, the legal importance in the country is significant, since it has been raised to the public interest through Decree No. 36567 of the Ministry of Science, Technology and Telecommunications, of March 28, 2011. Its recital 4 covers its importance and the necessary interinstitutional collaboration: Nanotechnology is one of the technologies [...] with great potential impact on the quality of life and the generation of the next industrial revolution, which is why the country must coordinate the efforts of key actors in education, research, productive sectors, governmental and non-governmental organizations [7].

On the other hand, it must be pointed out that the Costa Rican legal system has other provisions that must be consonant with the promotion of this technology, such as consumer protection. In Costa Rica, consumer protection is included in the Political Constitution, in article 46, which states: "Consumers and users have the right to protection of their health, environment, security and economic interests; to receive adequate and truthful information; to freedom of choice and fair treatment" [8].

The development of these rights can be found in Act 7472 on Promotion of Competition and Effective Defense of the Consumer; specifically becomes effective through the application of article 32 , which incorporates in literal a) the right of consumers to protection against risks that may affect their health, safety and the environment. In the same article through the literal c) is recognized consumer's right to information: "Access to information, accurate and timely, on the different goods and services, with correct specification of quantity, characteristics, composition, quality and price" [9]. From the joint interpretation of both rights, the National Consumer Commission stated that "the main objective of the right of information, is the consumer's knowledge of all the conditions of the negotiation that will be made and the characteristics of the products marketed, to avoid the purchase of those harmful to health or for their own money" [10]. On the other hand, as a duty of the merchant and the producer, it is estab- 
lished that they must: "Inform the consumer sufficiently, in Spanish and clearly and truthfully, about the elements that directly affect their consumption decision. It must be informed of the nature, composition, content, weight and, where appropriate, of the characteristics of the goods and services, the cash price on the packaging, the container, the container or the product label, the gondola or the shelf of the commercial establishment, as well as of any other determining factor". This has been developed by the National Consumer Commission who ensures that: "The offer, promotion or advertising of goods and services must be made according to the nature of them, their characteristics, conditions, content, weight when appropriate, utility or purpose so as not to mislead or deceive consumers" [11].

Within the framework of this regulation, it is aligned with most countries since citizen security is extracted from the Universal Declaration of Human Rights of 1948-numbers 3 and 25-and the International Covenant on Economic, Social and Cultural Rights of 1966-numbers 11 and 12 [12]. This article considers whether nanotechnology deserves an express regulation to guarantee the aforementioned rights in a country like Costa Rica, where products with nanostructures will continue to grow, given that the Ministry of Science, Technology and Telecommunications is entrusted to public entities and private [...] to contribute with the contribution of economic, logistical and technical resources for the realization of scientific research [13].

Given this situation of uncertainty, we must ask ourselves if it is appropriate to apply the precautionary principle to reduce risks of lack of protection of the aforementioned rights. The application of the precautionary principle in the area of food is framed in the field of human health and has already been applied and developed in Costa Rica, as reflected in Resolution 2006-017747 of the Constitutional Chamber of the Supreme Court of Justice of Costa Rica: It is necessary to implement the precautionary principle when an activity is posed as a threat to human health or the environment, precautionary measures should be taken even when some cause and effect relationships have not been established in a scientific manner in its entirety [...]. The operation of the precautionary principle in this area is very simple and means that when an activity produces or causes threats or probabilities of serious and irreversible harm to human health, precautionary measures should be adopted, the causal effects are not scientifically established [14].

Under this jurisprudential line, the principle must be applied to nanotechnology when these precepts are given by pertinent and proportional measures [12], to allow the advancement of technology. Possible advantages and disadvantages have been discussed in relation to these measures-express regulation-which is necessary to consult, in this case the community involved with nanotechnology in Costa Rica, to make sure that it is necessary to apply this principle in nanotechnology and in what terms, as well as to identify possible opportunities and avoid negative effects. 
This, according to the tracking that has been done, is the first article of its kind, involving people representative of the community involved with nanotechnology and institutions in charge of ensuring the safety of the citizen's health, which uses surveys to find out their opinion not only about the importance of regulating but also about the relevance of it. In this case, the community manifests itself in favor of regulation and in what terms it must be advanced to avoid its possible negative effects. This study should be taken as a first step in Costa Rica, to initiate the planning of a regulation as well as the means of public participation, to count on the commitment of all social strata.

In the literature, surveys have been carried out regarding the perception of the public during the last years. [15]-[19] are studies related to the perception of the public, being able to verify the different perceptions of risk that exists between researchers and consumers, mainly due to information asymmetry. However, there is no previous work, under our knowledge, to make an approach that includes the productive, academic and political sector in a specific context, as the first step towards building a participatory construction of nanotechnology regulation.

In these terms, to deepen the need for regulation, institutions from other contexts are asked to carry out this type of study, due to its economic and legal implications as well as to assess the need for regulatory convergence at an international level.

\section{Methodology}

A survey of 79 people was conducted in the age ranges presented in Figure 1.

80 percent of the participants currently live in Costa Rica and 20 percent in a country other than Costa Rica. Likewise, the exhibition tries to represent the community involved with nanotechnology and institutions in charge of ensuring the safety of the citizen's health. Figure 2 shows the percentages of job profiles of the different respondents and Figure 3 shows the specific fields in which they perform their functions:

Once the sample is delimited, the opinion survey is made to each participant and each answer is analyzed to know the position in front of the debate on the express regulation of nanotechnology, and see if it is possible to enrich it with alternative positions given the characteristics of the Costa Rica context.

In addition, from the point of view of the objective of the survey, it is an analytical survey, since although the literature has generally been in favor of regulation, it tries to contrast the hypothesis that in Costa Rica it would be appropriate to have with an express regulation of nanotechnology since it can contribute to the protection of the citizen's health.

The survey includes 8 questions, each with a purpose, as reflected in Table 1. Each question has been chosen to be questions worked on in the literature, as well as their possible answers, as will be explained in the following sections. 6 out of 8 questions are multiple choice test types, leaving the possibility that the res- 
pondent could enrich the questionnaire with an open response. The other 2 questions, the only possible answers are yes or no.

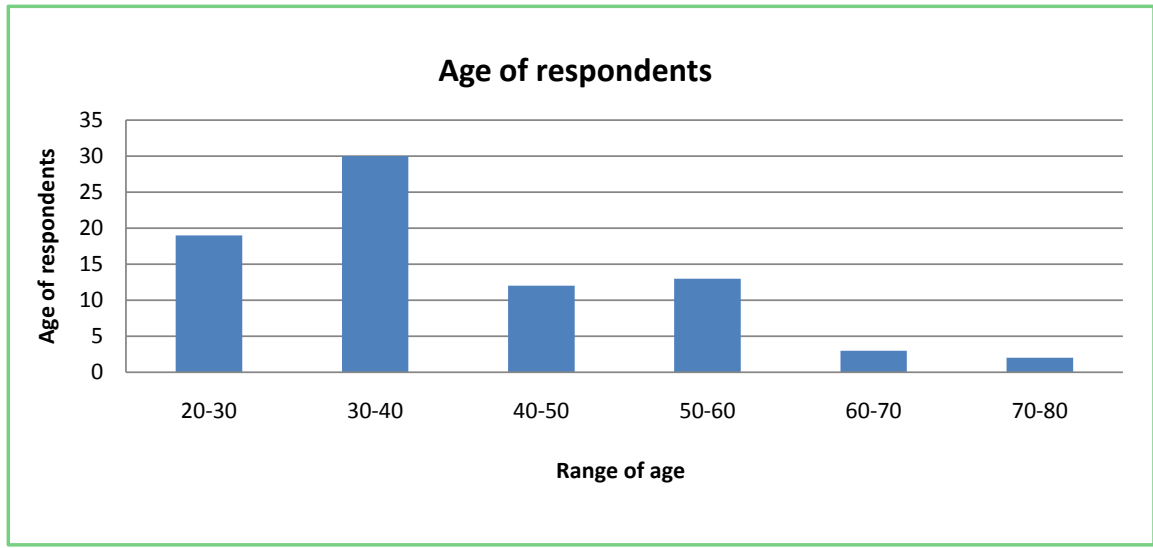

Figure 1. Range of age of respondents.

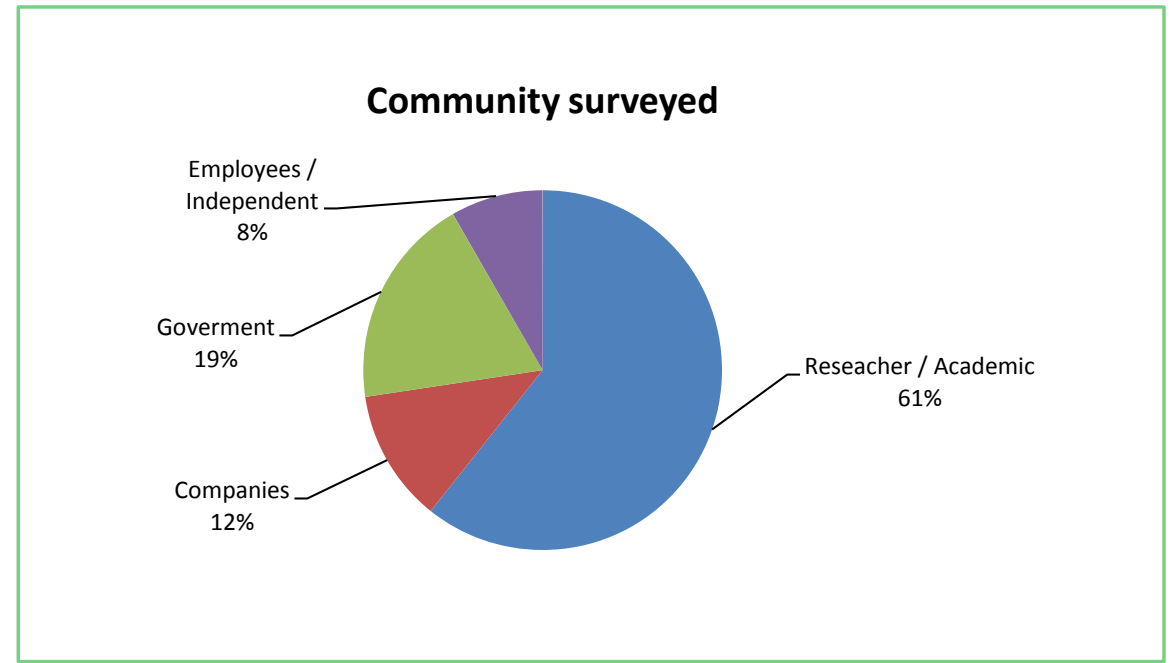

Figure 2. Percentage of people surveyed dedicated to research, businesses, government positions as well as employees or independents.

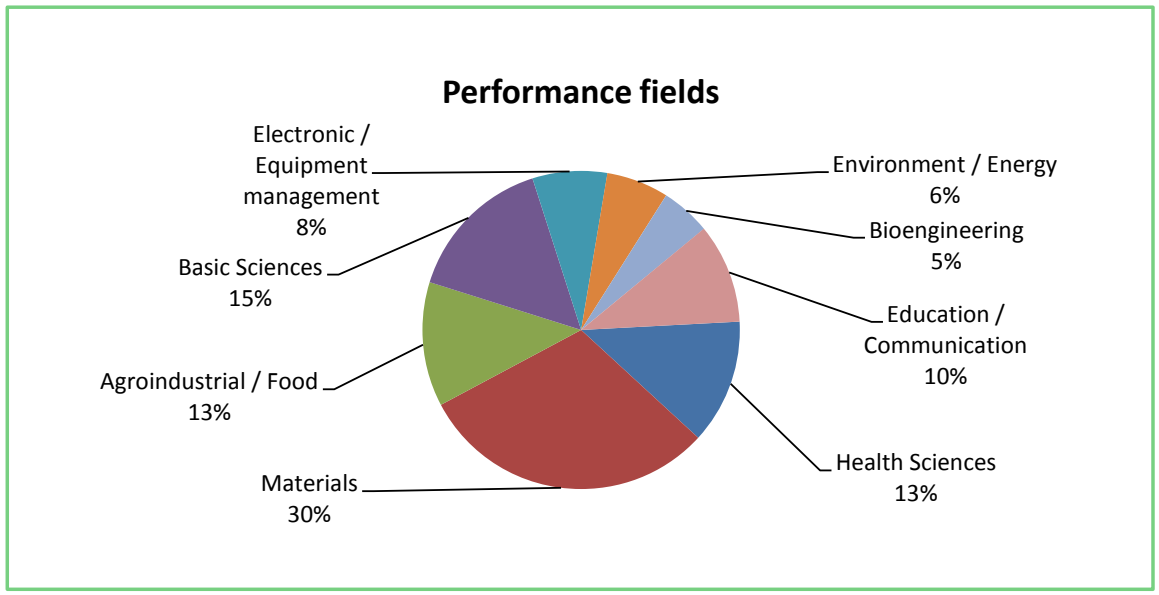

Figure 3. Performance fields of the respondents. 
Table 1. Survey questions and purpose of each question.

\begin{tabular}{ll}
\hline Questions & \multicolumn{1}{c}{ Purpose } \\
\hline $\begin{array}{l}\text { 1) Which one(s) do you consider to be the main } \\
\text { advantages that the regulation of }\end{array}$ & To identify possible advantages of an express \\
nanotechnology would generate for the sector to & regulation of nanotechnology to know its need. \\
which you belong? & \\
$\begin{array}{ll}\text { 2) Which one(s) do you consider to be the main } \\
\text { advantages that the regulation of }\end{array}$ & To identify possible disadvantages of an express \\
nanotechnology would generate for the sector to & regulation of nanotechnology to know its need. \\
which you belong? & To know the opinion of whether the advantages \\
$\begin{array}{l}\text { 3) Do you consider that the regulation of } \\
\text { nanotechnology for the sector to which you } \\
\text { belong is necessary? }\end{array}$ & $\begin{array}{l}\text { are considered of greater or lesser weight than the } \\
\text { disadvantages, to assess their need. }\end{array}$ \\
$\begin{array}{ll}\text { 4) Your answer to question } 3 \text { is due to } & \text { To understand the reason why the advantages or } \\
\end{array}$ & disadvantages have more weight.
\end{tabular}

5) Which institution should be in charge of having the responsibility to control the

To specify the institution that should assume the nanotechnological processes for the sector to which you belong in Costa Rica? control functions of nanomaterials in Costa Rica.

6) Mention at least five parameters that the institution should consider to authorise or deny the inclusion of nanomaterials in a product.

To identify parameters in the decision-making model.

7) Do you think that this institution should have a model for decision making in order to guide in the task of authorising the use of nanomaterials in the products of your sector?

To point out the need for the decision-making model to prioritize in the construction of regulation.

8) Ponder the utility of a model of this type.

To know the utility of the decision-making model to prioritize in the construction of regulation.

\section{Results and Discussion}

Below are the different results obtained. For this, the first section is the need to regulate nanotechnology in Costa Rica, where the results of the first 4 questions of the survey are addressed. Subsequently, in the following section, the decision-making institution and decision criteria are analyzed, in terms of the parameters of the nanomaterials, encompassing the answers of questions 5 and 6. Finally, in the section of the decision-making model and its importance, the results of questions 7 and 8 will be presented.

\subsection{The Need to Regulate Expressly Nanotechnology in Costa Rica}

In order to know the pertinence of the express regulation of nanotechnology, four questions of Table 1 were used, oriented to know the main advantages and disadvantages that it would entail, as well as if it is necessary or not, and the justification for it.

\subsubsection{Possible Advantages of an Express Regulation of Nanotechnology}

The first question asked is conceived by thinking about the advantages that a new express regulation of nanotechnology can bring, according to the respondents. Therefore, it reads as follows: Which one(s) do you consider to be the 
main advantages that the regulation of nanotechnology would generate for the sector to which it belongs? Taking into account that the questions are multiple choice test types, 165 total answers were collected. Below the different percentages of each response are presented, see Figure 4.

Among the different possible advantages of an express regulation of nanotechnology is that it could grant greater protection to the consumer [20]. In this case, insurance is understood when it is used under normal conditions and there is no risk, or there is a minimum risk, considered admissible. This possible advantage was the most voted, obtaining 31 percent of the votes.

The second possible advantage included in the questionnaire was to promote the regulation of nanomaterials in specific sectors [21]. That is, it is pertinent not only that there is an express regulation of nanotechnology, but that it must be specific and not generic. This possible advantage considers that the express regulation would consolidate framework rules and principles by virtue of which specific regulation would be generated, according to the particularities of each sector. We can consider as an example of this way of regulating nanotechnology the case of the European Union, which has different specific European regulations, such as in the food or cosmetics sector. This possible advantage was the second most popular among the respondents, reflecting 27 percent of the responses.

The third proposed advantage is that it would help to improve the information of the consumers before the choice of the product [22]. In the context of the European Union it has been considered opportune that it can influence the decision to purchase these products [22]. However, in other contexts such as the United States of America, the Food and Drug Administration (FDA) has stated that it depends on variables such as the process to which the nanomaterial is subjected and the type of nanomaterial and therefore the mere fact of saying that includes nanomaterials is not relevant information for the consumer [23]. 21 percent of the responses estimated that this would be an advantage, becoming the third main advantage.

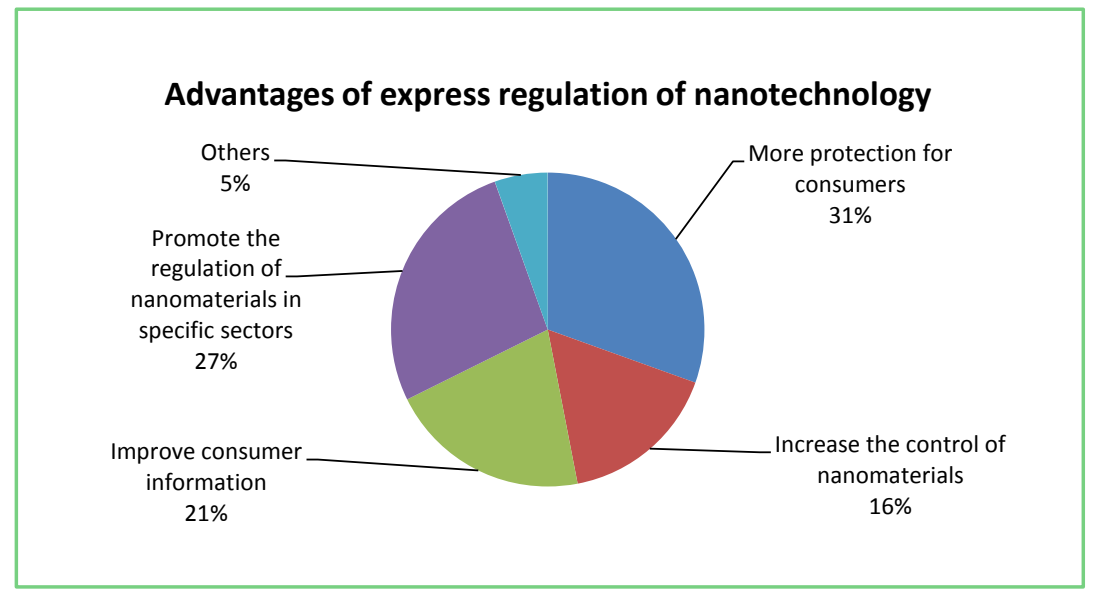

Figure 4. Advantages of an express regulation of nanotechnology. 
The fourth possible advantage is that it would help to control the nanomaterials market by having them identified [24]. This advantage finds explanation in the existing difficulty to collect data on the nanomaterials used in an aggregate manner. In addition to applying statistical techniques and constructing descriptive and predictive models to detect trends, with the advancement of the state of the art on the toxicity of different nanomaterials, we can act to be able to manage what nanomaterials and in what quantity are found in the products, in order to have a better control of the risk. This allows that toxic nanomaterials that can harm the consideration of this technology do not circulate. This is also useful if there is uncertainty, in order to prioritize studies of toxicity in silico, in vitro and in vivo. This advantage has 16 percent of the answers.

On the other hand, the possible advantages included by the respondents, different from those proposed by the survey, accounted by 5 percent of the responses. They were the following: 1) To have control over the environmental impact of these nanomaterials; 2) to generate support policies for the materials sector; 3) to have control in manufacturing and to know how to make the final disposition of the product; 4) to meet international standards; 5) improve information at the material level; 6) to develop intellectual property issues related to nanotechnology.

It can be concluded that in terms of possible advantages, the main ones pointed out by the respondents are that it would allow the development of regulation in specific sectors and provide greater consumer security. Therefore, they should be fundamental principles over which the express norms are built. Other advantages of less importance, but which should also be taken into account in order to configure an adequate regulation, are the improvement of the information given to the consumer and the increased control of nanomaterials.

\subsubsection{Possible Disadvantages of an Express Regulation of Nanotechnology}

The survey, then, addresses the possible disadvantages that prevent the development of legislative processes capable of crystallizing a regulation of nanotechnology. That is to say, in the absence of prior regulation, it is not only difficult to foresee the advantages that would be obtained with a new regulation but also the disadvantages. For this reason, the people questioned are asked the following question: 1 . Which one(s) do you consider to be the main disadvantages that the regulation of nanotechnology would generate for the sector to which you belong? A series of possible disadvantages reported in the literature were included. Of the 105 responses obtained, the results are presented below, see Figure 5.

Of the possible disadvantages rescued from the literature and included in the survey, the first one that was included was the provocation of panic among consumers [25]. This possible disadvantage refers to what information is exactly being reported, if the effects derived from the inclusion of nanotechnology in the products are not known with certainty. When applying the precautionary prin- 
ciple, consideration should be given to the non-involvement of commercial exchanges; a negative image of this technology can be created if the appropriate information is not channeled through the appropriate means. 13 percent of the responses point to this panic as a possible effect of the express regulation of nanotechnology.

The second possible disadvantage included in the survey was that it could be an obstacle to the development of nanotechnology [26]. The regulation has the state limits of where it is produced and that jurisdiction cannot be overwhelmed, an inadequate policy can relegate to a competitive unfavorable position to national productive sectors. The regulation if it is not permissive or flexible enough, evaluating the possible risks in an appropriate way, can row against this technology. To avoid unnecessary obstacles, it must be based on a risk assessment aligned with the development of the state of the art. This concern is reflected in 22 percent of the responses.

The third possible disadvantage proposed was inadequate regulation [27]. This can occur for different reasons: For inappropriate design of incentives, incoherent precepts with the general purpose of regulation, political and economic interests, risk assessment of certain nanomaterials without scientific basis or unnecessary burdens to producers, among others. The concern about this possible disadvantage is the biggest, representing 42 percent of the answers. Later, it will be asked about key factors such as the parameters on which a nanomaterial must be authorised or the use of a decision-making model.

The fourth possible disadvantage included in the survey was the allocation of resources [28]. This shows a concern for the efficiency of the application process of nanotechnology regulation. Given the technical and scientific difficulties to limit the uncertainty in the consumption of products that incorporate nanotechnology, the demand for resources can be a problem in terms of application. It is related to inadequate writing, since if it is constructed in a timely manner, it should consider the technical and economic possibilities of the means of control to apply it. 13 percent of the answers express this concern.

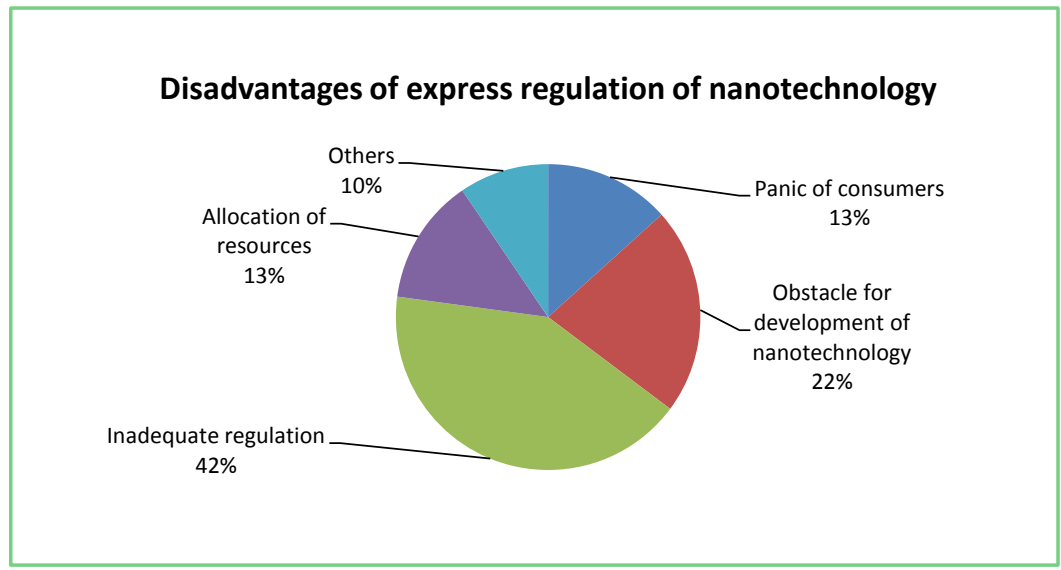

Figure 5. Disadvantages of an express regulation of nanotechnology. 
When having the option of including other possible disadvantages, the respondents indicated in addition to those expressly collected in the survey, the following: 1) to overload of information to the consumer; 2) to confuse the consumer; 3) undue intervention in each of the fields of action and 4) obstruction of free trade. These concerns are reflected in 10 percent of the responses.

It can be concluded that regarding the possible disadvantages, the main concerns are that the regulation is inadequate and that it could decelerate the development of nanotechnology in the country. In this sense, if the process of creating regulation and the inclusion of criteria were raised in a participatory manner, the main possible mistrust could be reduced. Other concerns, of less importance, although not ignorable, are the amount of resources that will be allocated to apply the regulation or the possible effects in relation to the consumer such as the generated panic, over information or confusion. In this sense, it would be significant if a political commitment on the part of the institutions is specifically included in the regulation to disseminate relevant information on nanotechnology so that citizens are aware of it and are not uninformed or over informed.

Once the possible advantages and disadvantages of the express regulation of nanotechnology have been addressed, the question arises whether it is necessary. Despite the advantages, is it better not to regulate given the possible disadvantages or vice versa? The following question was posed: Do you consider that the regulation of nanotechnology for the sector to which you belong is necessary?

The respondents mostly opted for an affirmative answer, as we can see in Figure 6, giving greater importance to the possible advantages than to the disadvantages. 92.4 percent of the answers were yes, while 7.6 percent were no.

Once known the contribution of express regulation of nanotechnology, what are the factors that should be considered in the regulation? That is, what is the justification for this regulation? The question formulated was: "Your answer to question 3 is due to". The answers are reflected in Figure 7.

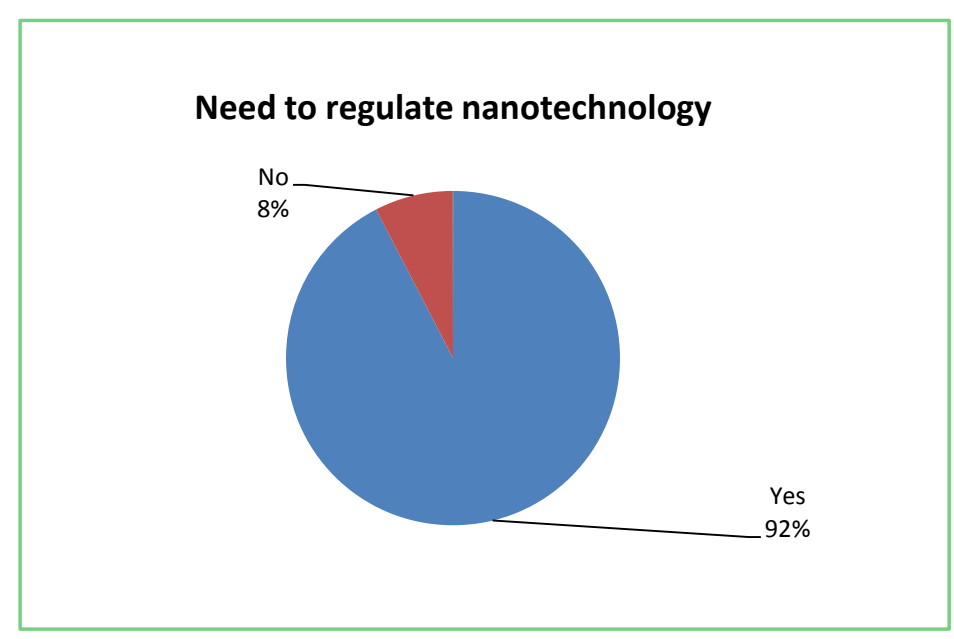

Figure 6. Need to regulate nanotechnology. 


\section{Justification of the regulation of nanotechnology}

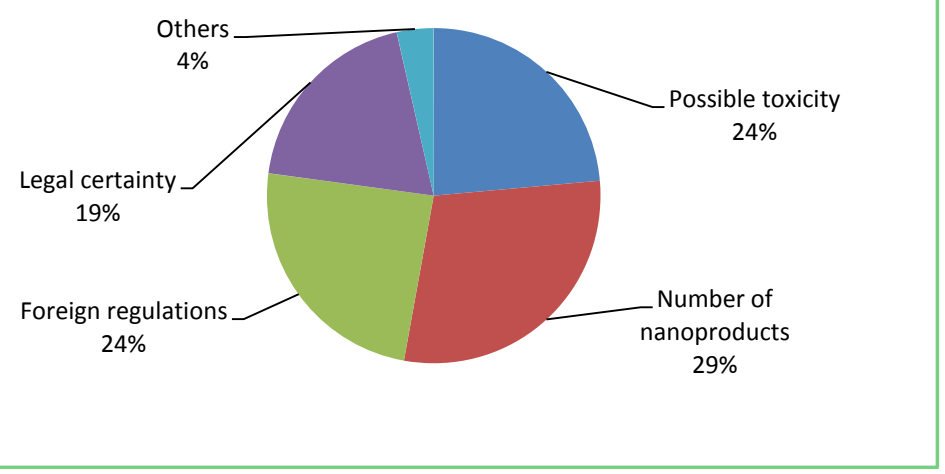

Figure 7. Justification of the regulation of nanotechnology.

The first option included was possible toxicity, given that although advances have been made on the toxicity of nanomaterials, measurement under unrealistic conditions [29], the variety of nanomaterials and applications [30] and lack of in vivo assays [31], provokes that there are still gaps in the toxic potential that can be expressed [32]. This justification represents 42.3 percent of the total responses.

The second reason why the regulation of nanotechnology is justified is the number of nanoproducts, given that there is a significative number of products with nanotechnology in the market [33]. This leads to an increasing exposure to these nanomaterials, and this variable must be kept in mind for the evaluation of the risk involved. This is the main reason that respondents indicate, representing 52.6 percent of the answers.

The third proposed reason is the alignment with foreign regulations [34]. In this way, if the same standards are applied, those standards can be assured that other countries also comply with to protect the health of consumers. On the other hand, in contractual terms, transaction costs decrease [35] between companies with domicile in different countries or that develop their economic activity in different countries. This justification received 43.6 percent of the answers.

The fourth reason is about legal certainty, since although nanotechnology is not regulated explicitly, companies invest in nanotechnology to improve their products [36], assuming the present uncertainty. At any time, a regulation can be promoted and crystallized against the interests of certain companies. The percentage of responses to this option was 34.6 percent.

Other justifications were indicated by the respondents assuming 4 percent of the total responses: 1) Risk assessment of risk to health and environment; 2) to provide information to the citizen and 3) to ensure that it is applied for peaceful purposes. The only justification given against the regulation of nanotechnology was from the investigative point of view, since regulation should not limit the researcher's autonomy. 


\subsection{Decision-Making Institution and Criteria}

As a result of the previously mentioned concerns, one aspect to be foreseen is the organization in charge of authorizing or denying the commercialization of products with nanomaterials in the market. In Costa Rica there are several institutions capable of assuming this task, so question 5 raises the following question: Which agency should be responsible for having the responsibility to control the nanotechnological processes for the sector to which it belongs in Costa Rica? The answers are reflected in Figure 8.

The preferred option in statistical terms is Laboratorio Nacional de Nanotecnología-Centro Nacional de Alta Tecnología (LANOTEC-CENAT) with 43.4 percent of the answers. However, the Ministry of Science, Technology and Telecommunications as well as the Ministry of Health follows it closely with 26 percent and 25 percent respectively. It must be said that the possible answers are not exclusive since, depending on the sector, different ministries may assume the responsibility of controlling these processes or even involving several bodies in a decision-making process. The fact that LANOTEC-CENAT is the most voted institution being unelected, can also help to give clues about its inclusion in the decision process. For example, the scenario in which LANOTEC-CENAT would be responsible for the study and development of investigations so that according to this opinion, the Ministry in charge can make a decision. Likewise, the possibility of creating a new decision-making institution was also assessed, although if total responses were taken as a reference, the support was not so high compared to the existing institutions ( 8 percent chose a new decision-making body).

Because the present article does not have the purpose of proposing an organizational structure capable of assuming these functions in an efficient manner, the literature is entrusted to understand mainly the internal structure and the allocation of resources and competences to be able to undertake this function.

In conclusion, as shown in Figure 8, the respondents expressed a favorable opinion regarding the absorption of functions of authorization and control of nanomaterials by existing institutions. Different Ministries that could apply the regulation of nanotechnology are indicated, so it can be concluded that it is more favorable for the specific regulations of each sector to be distributed, instead of being a specific Ministry responsible for centralizing these functions. In addition to all the institutions that are considered, the most supportive is an unelected institution, and since it has no power to authorize or deny, it would be advisable to take it into account so that its opinion has weight when deciding a determined elected institution, if it is not directly empowered to do so.

\section{Decision Criteria}

Regarding the parameters to be able to authorize or deny the commercialization of a nanomaterial, there are several properties that may be related to the level of toxicity expressed by a certain nanomaterial, being advisable as indicated [37], to consider both the properties of the material in general-such as the size of the particles [38] or aggregation state [39] properties of the chemical components- 


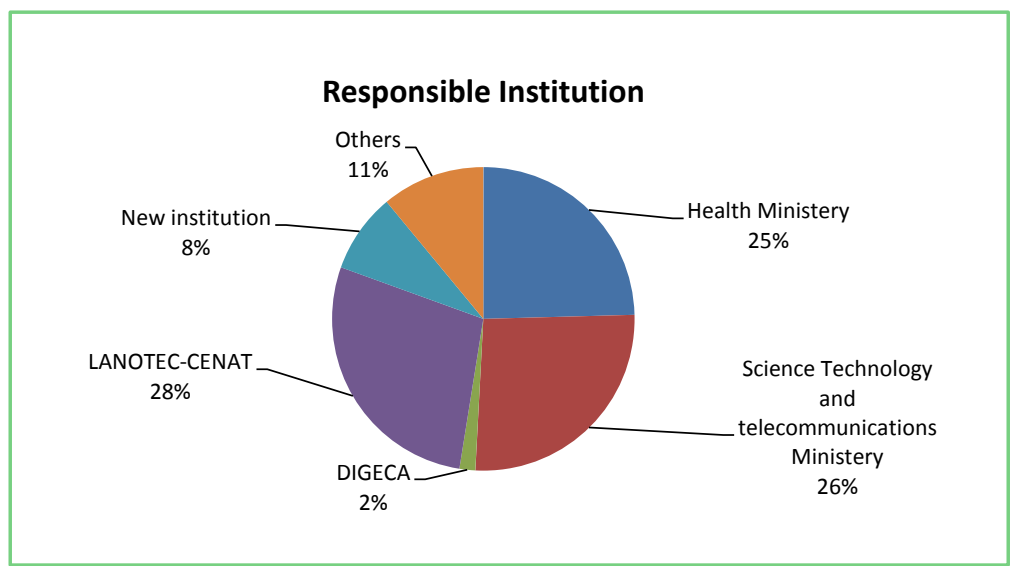

Figure 8. Decision-making institution on nanotechnology.

like purity [40] as well as the dependent properties of the environment-like solubility [41]. In question 6, respondents are asked what the parameters should be taken into consideration to assess toxicity. The proportion of the answers is illustrated in Figure 9.

Of the proposed parameters, 22 percent of the responses indicate the composition of the nanomaterial followed by the purity of the same, with 18 percent. The size and the process to which it is submitted have 16 percent of the votes. The form accumulates 12 percent and density, the least voted with 11 percent. Regarding the aggregated parameters, they represent 5 percent of the answers, including the following: 1) Persistence in the soil and its bioconcentration; 2) application of the nanomaterial; 3) physicochemical properties; 4) concentration; 5) cytotoxicity studies; 6) biocompatibility; 7) bioavailability; 8) life cycle of the nanomaterial; 9) aggregation; 10) agglomeration; 11) particle size distribution; 12) standardization; 13) sterilization.

On the other hand, as seen in Figure 9, a large number of parameters should be considered for decision making with distributed importance, being the composition, purity, process and size the most answered. This suggests that a model in which these variables can be taken into account or a model that has a different approach as variables at the molecular level is necessary, since an intuitive decision can be counterproductive given the complexity of each case.

\subsection{Decision-Making Models and Their Importance}

Once considered the need to regulate nanotechnology, given its advantages and disadvantages, and its justification, it is convenient to ask if there should be a model of decision making to authorize or deny the commercialization of a nanomaterial. Some of the advantages that a model can provide are the improvement of efficiency in time and resources so that the best decision can be made with the information available [29]. Models have been built, which have been trained with experimental data from the literature, since it is difficult to consider that without the computational capacity one can understand the risks that can be 
derived from the life cycle of a nanomaterial [42]. Some predictive models have been proposed as [43] with MLR y MLR-EM technique testing $48 \mathrm{Fe}_{2} \mathrm{O}_{3}$ and $\mathrm{Fe}_{3} \mathrm{O}_{4}$ nanoparticles, and CdSe quantic dots [44] applying perturbation theory testing 41 nanoparticle, 7 of them metallic nanoparticles or [45] with Montecarlo technique and 24 metal oxide nanoparticles tested.

Therefore, question 7 is: Do you think that this body should have a model for decision making that can guide you in your task of authorizing the use of nanomaterials in the products of your sector? 77 out of 79 responses were affirmative, representing 97.5 percent of the total, even being higher than the percentage that supports the creation of a specific regulation. They are represented by Figure 10.

Once the question about the need of the decision-making model has been answered, it is interesting to know the estimated utility of this model on the respondents. In this sense, a last question was introduced that reads as follows: "Ponder the utility of a model of this type." As can be seen in Figure 11, the 96.1 percent of the answers were that it would help or help a lot in decision-making.

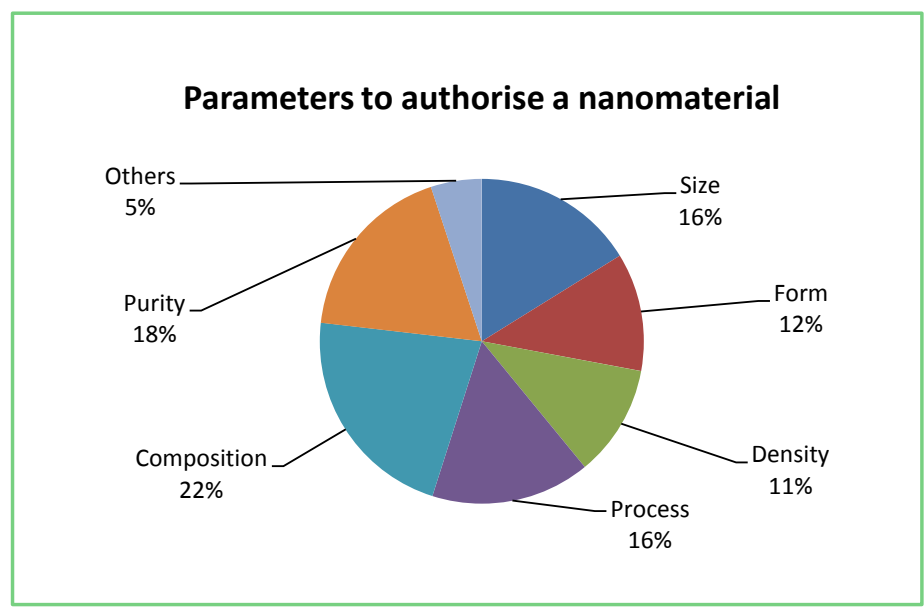

Figure 9. Parameters to authorize a nanomaterial.

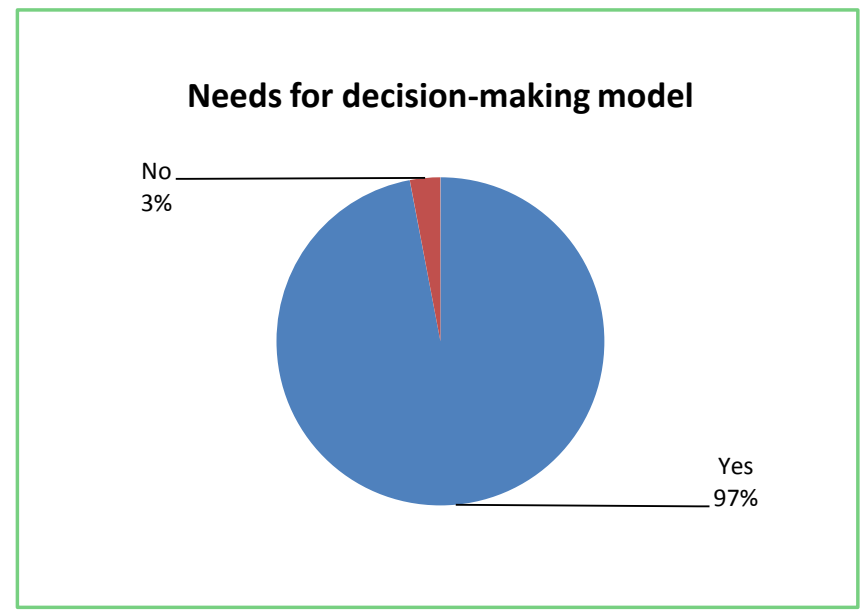

Figure 10. Need for decision-making model. 


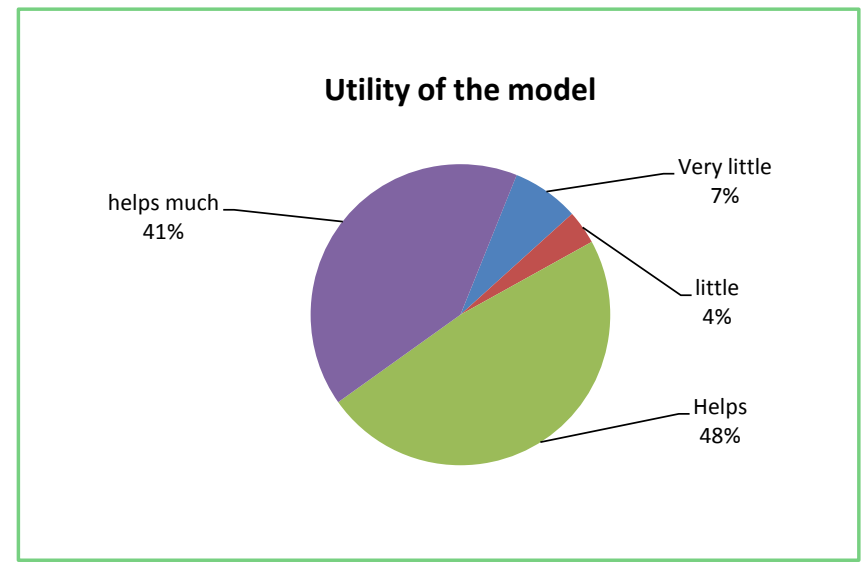

Figure 11. Need for a decision-making model.

From questions 7 and 8 , it can be inferred that the model should be the pillar on which the decision to authorize or deny nanomaterials is made, which is a fundamental aspect of regulation. The interest on the part of the community in this model is high given the great convergence of opinions. The construction of this model should be established as one of the main specific objectives of regulation. Studies should be carried out on the different alternatives of the model, fulfilling the required criteria taking advantage of the value of the main findings of this study, given that it is the first time that the community of experts in the Costa Rica context has been investigated.

\section{Conclusions}

Through this study, the different regulatory aspects discussed in the literature have been proposed in the context of Costa Rica and thus to know if the opinion of the expert's community is favorable or unfavorable to create a regulation, based on the precautionary principle, and if so, on what terms.

In the first place, the community surveyed-constituted by people involved in nanotechnological processes and consumer health protection through academia, companies and the government-considers that the express regulation of nanotechnology is necessary, mainly due to its possible toxicity and the increasing exposure to which the citizen is subjected. Although possible disadvantages are pointed out-mainly, generating inadequate regulation or a possible brake on the development of nanotechnology-they are compensated with the possible advantages that can arise, which are mainly to protect the consumer and provide specific regulations to the different productive sectors.

It should be considered that the regulation is applied by institutions in a distributed manner, with considerable weight given to the opinion of specialized technical bodies. With existing bodies and the absorption of functions efficiently should be sufficient to apply it to the context of Costa Rica, although studies should be conducted on the allocation of resources and skills to optimize how these functions should be assumed to reduce unnecessary expenses and structures, another of the possible disadvantages indicated by the respondents. 
Due to the high number of weight parameters as well as concerns regarding toxicity and increased exposure to citizens, it is important to have a model in which decisions are supported; it must be a sufficiently robust and validated model so that it does not slow down the advance of nanotechnology or that it constitutes inadequate regulation in terms of inconsistencies or lack of incentives.

\section{Acknowledgements}

Avoid the stilted expression, "One of us (R. B. G.) thanks ..." Instead, try "R. B. G. thanks". Special gratitude is extended to the CYTED NANOCELIA Network for its financial support in order to carry out research in the Laboratorio $\mathrm{Na}$ cional de Nanotecnología (LANOTEC-CENAT-CONARE), San José, Costa Rica. On the other hand, it is also grateful to COLCIENCIAS for the scholarship of doctorate studies of one of the authors within their competence; in particular, the financial support is granted by this institution through the open call: "Convocatoria para Doctorado Nacional 757" of 2017. This original research is part of the project "Investigación en Derecho Internacional y Nanotecnología" registered in the Research Center of the Universidad Pontificia Bolivariana with registration number 766B-06/17-37.

\section{Conflicts of Interest}

The authors declare no conflicts of interest regarding the publication of this paper.

\section{References}

[1] Sercan Ozcan, N.I. (2017) Patent Information Retrieval: Approaching a Method and Analyzing Nanotechnology Patent Collaborations. Scientometrics, 111, 941-970. https://doi.org/10.1007/s11192-017-2325-y

[2] Douglas Henrique Milanez, L.I. (2014) Patents in Nanotechnology: An Analysis Using Macro-Indicators and Forecasting Curves. Scientometrics, 101, 1097-1112. https://doi.org/10.1007/s11192-014-1244-4

[3] Leonardo da Silva Sant'Anna, M.S. (2013) Nanomaterials Patenting in Brazil: Some Considerations for the National Regulatory Framework. Scientometrics, 100, 675-686. https://doi.org/10.1007/s11192-014-1300-0

[4] Lili Wang, A.N. (2013) Interdisciplinarity of Nano Research Fields: A Keyword Mining Approach. Scientometrics, 94, 877-892. https://doi.org/10.1007/s11192-012-0856-9

[5] Thara Prabhakaran, H.H. (2019) Competing, Complementary and Co-Existing Paradigms in Techno-Scientific Literature: A Case Study of Nanotechnology for Engineering. Scientometrics, 118, 941-977. https://doi.org/10.1007/s11192-019-03013-2

[6] Asociación Estrategia Siglo XXI (2006) Asociación Estrategia Siglo XXI. 2006. Estrategia Siglo XXI: Conocimiento e innovación hacia el 2050 en Costa Rica: síntesis de la visión y Plan de Medio Siglo en ciencia y tecnología en Costa Rica. Fundación Crusa, San José.

[7] Ministry of Science, Technology and Telecommunications (2011) Decreto Ejecutivo. No. 36567. 
[8] Political Constitution of Costa Rica (1949) San José.

[9] José, S. and Rica, C. (1994) Law 7472 de Promotion of Competence and Effective Defense of the Consumer.

[10] National Consumer Commission, Voto 316-00 (17 de 07 de 2000).

[11] National Consumer Commission, Voto 152-00 (National Consumer Commission 04 13, 2000).

[12] Fisher González, V. (2015) Agricultura y alimentación: El principio precautorio a la luz del derecho comparado y nacional. IUDEX, 103-123.

[13] Vega, J.R. (2017) Políticas nacionales de desarrollo de la nanotecnología en Costa Rica. Revista Digital Universitaria, 14.

[14] Supreme Court of Justice, 2006-017747 (Resolution 2006).

[15] Siegrist, M.K. (2007) Laypeople's and Experts' Perception of Nanotechnology Hazards. Risk Analysis: An International Journal, 27, 59-69.

https://doi.org/10.1111/j.1539-6924.2006.00859.x

[16] Cormick, C. (2009) Why Do We Need to Know What the Public Thinks about Nanotechnology? NanoEthics, 3, 167-173. https://doi.org/10.1007/s11569-009-0065-Z

[17] Gupta, N.F. (2015) Ethics, Risk and Benefits Associated with Different Applications of Nanotechnology: A Comparison of Expert and Consumer Perceptions of Drivers of Societal Acceptance. NanoEthics, 9, 93-108. https://doi.org/10.1007/s11569-015-0222-5

[18] Dalton-Brown, S. (2016) Public engagement and nanotechnology in Australia. Cambridge Quarterly of Healthcare Ethics, 25, 518-525. https://doi.org/10.1017/S0963180116000268

[19] Brunel, M.L. (2017) Is the Social Representation of Nanotechnology Anchored in that of GMOs? Journal of Risk Research, 21, 1-16.

[20] Bowman, D. and Hodge, G. (2007) A Small Matter of Regulation: An International Review of Nanotechnology Regulation. Science and Technology Law Review, 8, $1-36$.

[21] Chau, C.-F., Wu, S.-H. and Yen, G.-C. (2007) The Development of Regulations for Food Nanotechnology. Trends in Food Science and Technology, 18, 269-280. https://doi.org/10.1016/j.tifs.2007.01.007

[22] Aschberger, K., Rauscher, H., Crutzen, H., Rasmussen, K., Christensen, F.M., Sokull-Klüttgen, B. and Stamm, H. (2014) Considerations on Information Needs for Nanomaterials in Consumer Products. Commission Joint Research Centre Institute for Health and Consumer Protection, Brussels.

[23] Food and Drug Administration (2014) Guidance for Industry Considering Whether an FDA-Regulated Product Involves the Application of Nanotechnology. Food and Drug Administration, Silver Spring.

[24] Lyndon, M. (1989) Information Economics and Chemical Toxicity: Designing Laws to Produce and Use Data. Michigan Law Review, 7, 1795-1861.

http://www.jstor.org/stable/10.2307/1289204

https://doi.org/10.2307/1289204

[25] Conley, S. (2013) Anticipatory Governance in Practice? Nanotechnology Policy in Cambridge, Massachusetts. In: Hays, S., Robert, J., Miller, C. and Bennett, I., Eds., Nanotechnology, the Brain, and the Future. Yearbook of Nanotechnology in Society, Springer, Dordrecht, 373-392. https://doi.org/10.1007/978-94-007-1787-9_21

[26] Levi-Faur, D. and Comaneshter, H. (2007) The Risks of Regulation and the Regulation of Risks: The Governance of Nanotechnology. In: Hodge, G.A., Bowman, D.M. 
and Ludlow, K., Eds., New Global Frontiers in Regulation: The Age of Nanotechnology, Elgar, Cheltenham, 149-165.

[27] Ludlow, K., Bowman, D. and Kirk, D. (2009) Hitting the Mark or Falling Short with Nanotechnology Regulation? Trends in Biotechnology, 27, 615-620. https://doi.org/10.1016/j.tibtech.2009.07.007

[28] Lin, A. (2007) Size Matters: Regulating Nanotechnology. Harvard Environmental Law Review, 31, 349.

[29] Martirosyan, A. and Schneider, Y.-J. (2014) Engineered Nanomaterials in Food: Implications for Food Safety and Consumer Health. International Journal of Environmental Research and Public Health, 11, 5720-5750. https://doi.org/10.3390/ijerph110605720

[30] Wong, P., Ho, Y. and Chan, K. (2007) Internationalization and Evolution of Application Areas of an Emerging Technology: The Case of Nanotechnology. Scientometrics, 70, 715-737. https://doi.org/10.1007/s11192-007-0309-Z

[31] Livney, Y.D. (2015) Nanostructured Delivery Systems in Food: Latest Developments and Potential Future Directions. Current Opinion in Food Science, 3, 125-135. https://doi.org/10.1016/j.cofs.2015.06.010

[32] He, X. and Hwang, H.M. (2016) Nanotechnology in Food Science: Functionality, Applicability, and Safety Assessment. Journal of Food and Drug Analysis, 24, 671-681. https://doi.org/10.1016/j.jfda.2016.06.001

[33] Vance, M., Kuiken, T., Vejerano, E., McGinnis, S., Hochella, M., Rejeski, D. and Hull, M. (2015) Nanotechnology in the Real World: Redeveloping the Nanomaterial Consumer Products Inventory. Beilstein Journal of Nanotechnology, 6, 1769-1780. https://doi.org/10.3762/bjnano.6.181

[34] Chaudhry, Q., Scotter, M., Blackburn, J., Bryony, R., Boxall, A., Castle, L., Watkins, R., et al. (2008) Applications and Implications of Nanotechnologies for the Food Sector. Food Additives and Contaminants-Part A, 25, 241-258.

[35] Coase, R.H. (1960) The Problem of Social Cost. In: Gopalakrishnan, C., Ed., Classic Papers in Natural Resource Economics, Palgrave Macmillan, London, 87-137. https://doi.org/10.1057/9780230523210_6

[36] Bawa, R. (2013) FDA and Nanotech: Baby Steps Lead to Regulatory Uncertainty. In: Bagchi, D., Bagchi, M., Moriyama, F. and Shahidi, F., Eds., Bio-Nanotechnology: A Revolution in Food, Biomedical and Health Science, John Wiley \& Sons, Ltd., New York, 720-732. https://doi.org/10.1002/9781118451915.ch41

[37] EFSA (2018) Public Consultation on the Draft EFSA Guidance on the Risk Assessment of the Application of Nanoscience and Nanotechnologies in the Food and Feed Chain: Part 1, Human and Animal Health. Brussels.

[38] Baalousha, M. and Lead, J. (2013) Nanoparticle Dispersity in Toxicology. Nature Nanotechnology, 8, 308-309. https://doi.org/10.1038/nnano.2013.78

[39] Jiang, J., Oberdörster, G. and Biswas, P. (2009) Characterization of Size, Surface Charge, and Agglomeration State of Nanoparticle Dispersions for Toxicological Studies. Journal of Nanoparticle Research, 11, 77-89.

https://doi.org/10.1007/s11051-008-9446-4

[40] Padovani, G., Feitosa, V., Sauro, S., Tay, F., Durán, G., Paula, A. and Durán, N. (2015) Advances in Dental Materials through Nanotechnology: Facts, Perspectives and Toxicological Aspects. Trends in Biotechnology, 33, 621-636. https://doi.org/10.1016/j.tibtech.2015.09.005

[41] Laux, P., Tentschert, J., Riebeling, C., Braeuning, A., Creutzenberg, O., Epp, A., Luch, A., et al. (2018) Nanomaterials: Certain Aspects of Application, Risk Assess- 
ment and Risk Communication. Archives of Toxicology, 92, 121-141.

https://doi.org/10.1007/s00204-017-2144-1

[42] Toropova, A. and Toropov, A. (2015) Mutagenicity: QSAR-Quasi-QSAR-Nano-QSAR. Mini Reviews in Medicinal Chemistry, 15, 608-621. https://doi.org/10.2174/1389557515666150219121652

[43] Epa, V.C., Burden, F.R., Tassa, C., Weissleder, R., Shaw, S. and Winkler, D.A. (2012) Modeling Biological Activities of Nanoparticles. Nano Letters, 12, 5808-5812. https://doi.org/10.1021/nl303144k

[44] Luan, F., Kleandrova, V., González-Diaz, H., Ruso, J., Melo, A., Speck-Planche, A. and Cordeiro, M. (2014) Computer-Aided Nanotoxicology: Assessing Cytotoxicity of Nanoparticles under Diverse Experimental Conditions by Using a Novel QSTR-Perturbation Approach. Nanoscale, 6, 288-294. https://doi.org/10.1039/C4NR01285B

[45] Toropova, A., Toropov, A., Benfenati, E., Korenstein, R., Leszczynska, D. and Leszczynski, J. (2015) Optimal Nano-Descriptors as Translators of Eclectic Data into Prediction of the Cell Membrane Damage by Means of Nano Metal-Oxides. Environmental Science Pollution Research, 22, 745-757.

https://doi.org/10.1007/s11356-014-3566-4 